\title{
Detecção de Xanthomonas axonopodis pv. glycines em sementes de soja
}

\author{
Marcela Ribeiro Violatti ${ }^{1}$, Nilvanira Donizete Tebaldi ${ }^{2}$
}

${ }^{1}$ Engenheira Agrônoma, ${ }^{2}$ Docente do Instituto de Ciências Agrárias, da Universidade Federal de Uberlândia, Av. Amazonas s/n, Bloco 2E-121, Campus Umuarama, CEP 38.400-902,Uberlândia,MG, Brasil

Autor para correspondência: Nilvanira Donizete Tebaldi (nilvanira.tebaldi@ufu.br)

Data de chegada: 17/09/2015. Aceito para publicação em: 04/11/2015.

$10.1590 / 0100-5405 / 2127$

\section{RESUMO}

Violatti, M.R; Tebaldi, N.D. Detecção de Xanthomonas axonopodis pv. glycines em sementes de soja. Summa Phytopathologica, v.42, n.3, p.268-270, 2016.

Os genótipos de soja utilizados para a alimentação humana são suscetíveis a Xanthomonas axonopodis pv. glycines (Xag). A bactéria é transmitida pelas sementes e apresenta difícil controle, justificando a necessidade de realizar testes de sanidade de sementes antes da comercialização ou semeadura. Os meios de cultura para a detecção da bactéria em sementes devem ser práticos, rápidos e sensíveis. O objetivo do trabalho foi detectar a presença de Xag em sementes de soja, em meio de cultura semi-seletivo. Nos meios de cultura de semi-seletivo MXG com e sem antibióticos e de rotina 523 foi cultivada a suspensão bacteriana $\left(10^{9} \mathrm{UFC} \mathrm{mL} \mathrm{mL}^{-1}, \mathrm{OD}_{550}=0,5\right)$, diluída em série $\left(10^{-1}\right.$ a $10^{-}$ ${ }^{7}$ ), do isolado UFU C35 de Xag, em placas de Petri com 3 repetições para cada diluição. Após 4 dias foi quantificado o número de unidades formadoras de colônias por $\mathrm{mL}\left(\mathrm{UFC} \mathrm{mL}^{-1}\right)$. A análise estatística foi realizada a partir do teste
Kruskal-Wallis. Para detecção da bactéria nas sementes de soja foram avaliados cinco genótipos: 0012.UB010/11-P, 0012.UB1501/11-P, 0012.UB037/11-P, 0012.UB003/11-P e NT12 Paraná. Em Erlenmeyer foram colocadas 100 g de sementes e adicionados $200 \mathrm{~mL}$ de solução salina $0,85 \%$, incubados na geladeira por $18 \mathrm{~h}$. Os extratos das sementes foram diluídos em série $\left(10^{-1} \mathrm{a}\right.$ $10^{-2}$ ) e cultivados nos meios de cultura MXG com antibióticos e 523, com 6 repetições para cada diluição e incubados a $28^{\circ} \mathrm{C}$. Após 4 dias foi quantificado o número de $\mathrm{UFC}^{-1}$ de sementes. As médias dos tratamentos foram comparadas pelo teste de Tukey a $5 \%$ de probabilidade. O meio de cultura semi-seletivo MXG com e sem antibióticos não inibiu o desenvolvimento de Xag e o meio MXG com antibióticos foi eficiente para deteç̧ão da bactéria em sementes de soja de todos os genótipos avaliados, podendo ser usado em análises de rotina.

Palavras-chave: Glycine max, pústula bacteriana, soja para a alimentação humana.

\section{ABSTRACT}

Violatti, M.R.; Tebaldi, N.D. Detection of Xanthomonas axonopodis pv. glycines in soybean seeds. Summa Phytopathologica, v.42, n.3, p. 268270, 2016.

Soybean genotypes used as food are susceptible to Xanthomonas axonopodis pv. glycines (Xag). This bacterium is transmitted by seeds and is difficult to control, justifying the need of conducting seed health tests before commercialization or sowing. Culture media for bacterium detection in seeds should be practical, rapid and sensitive. The aim of this study was to detect the presence of Xag in soybean seeds on semi-selective culture medium. On the semi-selective culture medium MXG with and without antibiotics and on the routine culture medium 523 , the serial diluted $\left(10^{-1}\right.$ to $\left.10^{-7}\right)$ bacterial suspension $\left(10^{9} \mathrm{CFU} \mathrm{mL}-1, \mathrm{OD}_{550}=0.5\right)$ of the isolate UFU C35 from Xag was cultivated on Petri dishes with 3 replicates for each dilution. After 4 days, the number of colony forming units per $\mathrm{mL}\left(\mathrm{CFU} \mathrm{mL} \mathrm{mL}^{-1}\right)$ was quantified. Statistical analysis was performed according to Kruskal-Wallis test. For detection of the bacterium in soybean seeds, five genotypes were evaluated: 0012.UB010/11-P, 0012. UB1501/11-P, 0012.UB037/11-P, 0012.UB003/11-P and NT12 Paraná. In an Erlenmeyer, $100 \mathrm{~g}$ of seeds were added of $200 \mathrm{~mL}$ of $0.85 \%$ saline solution and incubated for 18 hours in a refrigerator. Seed extracts underwent serial dilution $\left(10^{-1}\right.$ to $\left.10^{-2}\right)$ and plating on the culture media MXG with antibiotics and 523, using 6 replicates for each dilution, followed by incubation at 28 ${ }^{\circ} \mathrm{C}$. After 4 days, the number of $\mathrm{CFU} \mathrm{g} \mathrm{g}^{-1}$ seeds was quantified. The means of treatments were compared according to Tukey's test at $5 \%$ probability. The semi-selective medium MXG with and without antibiotics did not inhibit the development of $\mathrm{Xag}$, and the medium MXG with antibiotics was effective to detect the bacterium in soybean seeds of all evaluated genotypes, which can be used in routine analyses.

Keywords: Glycine max, bacterial pustule, soybean for human food.

O consumo de soja para a alimentação humana tem se tornado crescente, devido aos benefícios atribuídos ao grão na prevenção de algumas doenças (6).

A preocupação com variedades voltadas para alimentação humana, refere-se à falta de resistência genética a determinados patógenos como Xanthomonas axonopodis pv. glycines, agente causal da pústula bacteriana. A bactéria é disseminada principalmente pelas sementes, as quais não apresentam diferenças visíveis entre sadias e infectadas, sendo fonte de inóculo e responsável pela introdução do patógeno em novas áreas (1).

Como medida de controle recomenda-se o uso de sementes sadias, identificadas a partir análises laboratoriais. Técnicas imunológicas e moleculares já foram descritas para a detecção de bactérias em sementes (9), no entanto, a utilização de meio de cultura semi-seletivo tem sido usado devido à especificidade, sensibilidade e facilidade na execução.

Os principais critérios para avaliação de um meio semi-seletivo são a seletividade e a eficiência na detecção de patógenos, com alta supressividade para micro organismos saprófitos e baixa repressividade para bactérias fitopatogênicas que se deseja detectar e/ou quantificar (3). A adição de antibióticos ao meio semi-seletivo visa diminuir o número de contaminantes e favorecer o desenvolvimento da espécie desejada (3). 
Assim, o objetivo do trabalho foi comparar a eficiência dos meios de cultura semi-seletivo MXG e de rotina 523, na detecção de Xanthomonas axonopodis pv. glycines em sementes de soja.

O experimento foi conduzido no Laboratório de Bacteriologia Vegetal, do Instituto de Ciências Agrárias, da Universidade Federal de Uberlândia. O isolado UFU C35 de Xanthomonas axonopodis pv. glycines, proveniente de sementes de soja de Indianópolis-MG e pertencente à coleção de trabalho do Laboratório, foi cultivado em meio de cultura 523. A suspensão bacteriana foi preparada em solução de $\mathrm{NaCl} 0,85 \%$, e ajustada em espectrofotômetro para $\mathrm{OD}_{550}=0,5\left(10^{9}\right.$ $\mathrm{UFC} \mathrm{mL}^{-1}$ ).

Para avaliação da supressividade e repressividade do meio de cultura foi feita a diluição em série $\left(10^{-1}\right.$ a $\left.10^{-7}\right)$ da suspensão bacteriana e o cultivo nos meios de cultura semi-seletivo MXG com e sem antibióticos e de rotina 523 .

O meio semi-seletivo MXG (7) foi constituído de1 L de água destilada, 0,8 de $\mathrm{K}_{2} \mathrm{HPO}_{4}, 0,6 \mathrm{~g}$ de $\mathrm{KH}_{2} \mathrm{HPO}_{4}, 0,7 \mathrm{~g}$ de extrato de levedura, $0,8 \mathrm{~g}$ de amido solúvel, $1 \mathrm{~g}$ de glicose, $15 \mathrm{~g}$ de ágar, $1 \mathrm{~mL}$ de verde metila ( $1 \%$ em $20 \%$ de etanol), aferindo o $\mathrm{pH}$ entre 7,2-7,4. Para o meio MXG com antibiótico adicionou-se, via esterilização por filtragem, $1 \mathrm{~mL}$ de cicloheximida (50 $\mathrm{mg} \mathrm{mL}^{-1} \mathrm{em}$ metanol 12,5\%) e $1 \mathrm{~mL}$ de cefalexina (50 $\mathrm{mg} \mathrm{mL}^{-1}$ solução aquosa) a cada litro de meio preparado, após autoclavagem.

Para cada diluição em série $\left(10^{-1}\right.$ a $\left.10^{-7}\right)$ foram utilizadas três placas de Petri. As placas foram incubadas a $28{ }^{\circ} \mathrm{C}$, por 4 dias e, em seguida, contado o número de colônias, calculando-se as UFC $\mathrm{mL}^{-1}$. Para a análise estatística as médias foram comparadas pelo teste de Kruskal-Wallis.

Para detecção de Xanthomonas axonopodis pv. glycines em sementes foram avaliados cinco genótipos de soja: 0012.UB010/11-P, 0012.UB1501/11-P, 0012.UB037/11-P, 0012.UB003/11-P e NT12 Paraná, provenientes de Indianópolis -MG, Uberlândia-MG, TapuiramaMG, Rio Verde-GO e Paraná, respectivamente.

Em Erlenmeyer foram colocadas $100 \mathrm{~g}$ de sementes e adicionados $200 \mathrm{~mL}$ de solução salina $0,85 \%$. A seguir, os Erlenmeyers foram incubados na geladeira por $18 \mathrm{~h}$. Os extratos das sementes foram diluídos em série $\left(10^{-1}\right.$ a $\left.10^{-2}\right)$ e cultivados nos meios de cultura MXG com antibiótico e 523, em placas de Petri, com 6 repetições para cada diluição e incubados a $28{ }^{\circ} \mathrm{C}$ por 4 dias, calculando-se o número de UFC $\mathrm{g}^{-1}$ de sementes.

As colônias suspeitas foram repicadas para meio 523, sendo realizados os testes de: Gram, Oxidação/Fermentação, YDC, asparagina, reação de hipersensibilidade em fumo e inoculação no hospedeiro.

O ensaio para a detecção da bactéria em sementes foi em esquema fatorial 2 x 5 (meios de cultura x genótipos), em delineamento inteiramente casualizado, com seis repetições de cada amostra. Os dados obtidos foram submetidos à análise de variância e as médias comparadas pelo teste de Tukey a 5\% de probabilidade utilizando o software SISVAR (2).

Quanto à supressividade e repressividade dos meios de cultura MXG com e sem antibióticos e o meio de rotina 523, não diferiram significativamente, variando de $5,4 \times 10^{9}$ a $9,6 \times 10^{9} \mathrm{UFC} \mathrm{mL}^{-1}$. Apesar de não ocorrer diferença significativa no número de colônias entre o meio 523 e o meio semi-seletivo MXG, foi observado redução visual no diâmetro das colônias de Xanthomonas axonopodis pv. glycines, no meio semi-seletivo MXG (Figura 1B e C), independente do uso ou não de antibióticos.

Resultados semelhantes foram descritos por Mehta et al. (4), na detecção de Xanthomonas axonopodis pv. malvacearum em sementes de algodão, em que os meios de cultura semi-seletivo e o padrão não diferiram estatisticamente no número de UFC $\mathrm{mL}^{-1}$. Para detecção de Xanthomonas axonopodis pv. vignicola em videira, o meio semiseletivo CCM também reduziu o tamanho das colônias da bactéria alvo (5).

$\mathrm{Na}$ detecção de Xanthomonas axonopodis pv. glycines em sementes de soja, o meio de cultura 523 e meio semi-seletivo MXG com antibióticos (Tabela 1) não diferiram estatisticamente entre si, com relação ao número $\mathrm{UFC}^{-1}$ de semente. Na média o genótipo NT12 Paraná apresentou maior número de UFC $\mathrm{g}^{-1}$ de semente $(0,78)$ não diferindo estatisticamente do genótipo 0012.UB010/11-P $(0,47)$. A bactéria foi detectada nas sementes de soja, em todos os genótipos avaliados.

Os isolados bacterianos detectados nas sementes de soja foram caracterizados como: Gram negativo, oxidação/fermentação: aeróbia estrita; com colônias mucóides, convexas, brilhantes, de coloração amarela em meio de cultura 523 e YDC, asparagina como única fonte de carbono e nitrogênio negativo, reação de hipersensibilidade em fumo e patogenicidade no hospedeiro positivos; caracterizando os isolados como Xanthomonas axonopodis pv. glycines.

O meio semi-seletivo apresenta vantagens quando comparado com o meio de rotina, como o meio semi-seletivo XCP1 para detecção de Xanthomonas axonopodis pv. phaseoli em sementes de feijão (10), que proporcionou a recuperação de maior número de UFC $\mathrm{mL}^{-1}$, facilitou a observação das colônias formadas e inibiu o crescimento de microrganismos indesejados. Assim como, o meio semi-seletivo
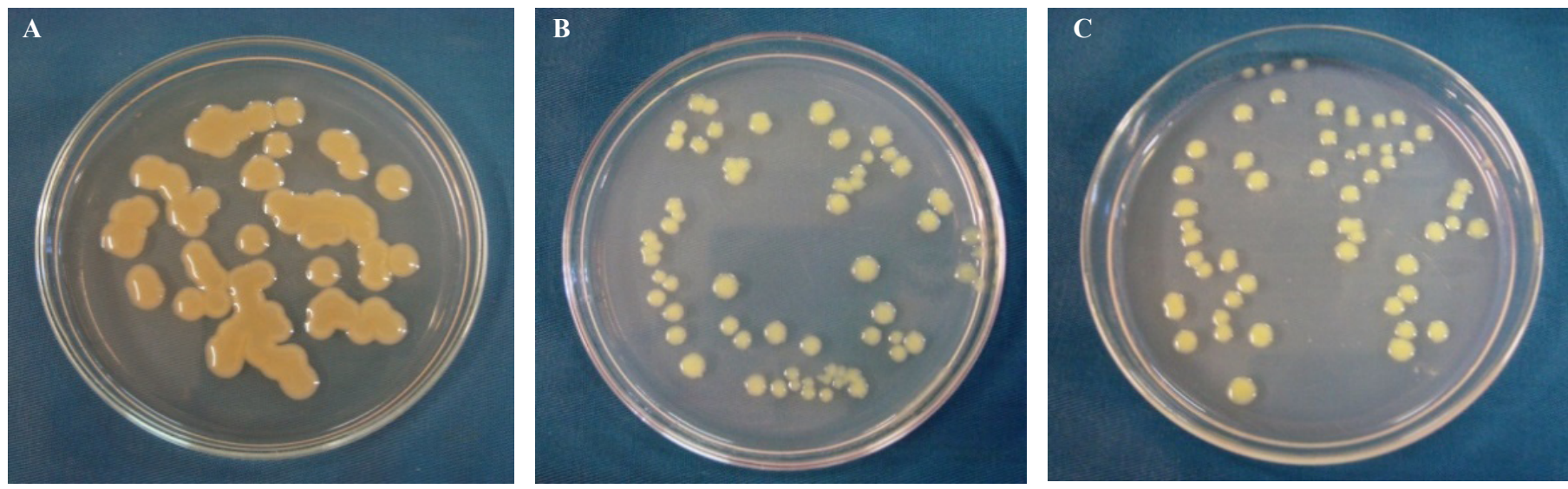

Figura 1. Colônias de Xanthomonas axonopodis pv. glycines, a partir da suspensão bacteriana, quatro dias após o plaqueamento. A) Meio de cultura 523. B e C). Meio de cultura semi-seletivo MXG, sem e com antibióticos, respectivamente. 
Tabela 1. Detecção de Xanthomonas axonopodis pv. glycines em sementes de soja, de diferentes genótipos, em meio de cultura não seletivo 523 e meio semi-seletivo MXG com antibióticos. Uberlândia - MG, 2013.

\begin{tabular}{|c|c|c|c|}
\hline \multirow{2}{*}{ Genótipos } & \multicolumn{2}{|c|}{ Meio } & \multirow{2}{*}{$\begin{array}{c}\text { Média } \\
\text { (UFC } \mathrm{g}^{-1} \text { sementes) }\end{array}$} \\
\hline & 523 & MXG & \\
\hline 0012.UB010/11-P & 0,58 & 0,35 & $0,47 \mathrm{ab}$ \\
\hline 0012.UB1501/11-P & 0,08 & 0,23 & $0,16 \mathrm{~b}$ \\
\hline 0012.UB037/11-P & 0,10 & 0,20 & $0,17 \mathrm{~b}$ \\
\hline 0012.UB003/11-P & 0,08 & 0,06 & $0,07 \mathrm{~b}$ \\
\hline NT12 PARANÁ & 0,72 & 0,87 & $0,78 \mathrm{a}$ \\
\hline Média (Meio) & 0,31 & 0,34 & \\
\hline
\end{tabular}

Médias seguidas por letras distintas, na coluna diferem entre si pelo teste de Tukey a 0,05 de significância.

PSA para detecção de Xanthomonas axonopodis pv. malvacearum em sementes de algodão (4), onde houve uma inibição do crescimento dos fungos contaminantes, e não interferiu no desenvolvimento da bactéria alvo.

Segundo Rabalho (8) ao desenvolver meio de cultura semiseletivo para detecção de Xanthomonas spp. em sementes de tomate, o meio apresentou alta eficácia devido à sua baixa repressividade, alta supressividade e baixo custo.

Portanto, o meio MXG poderá ser utilizado para a detecção de Xanthomonas axonopodis pv. glycines em sementes de soja, pois não inibiu seu crescimento, e a adição de antibióticos foi importante, pois inibiu o crescimento de microrganismos saprófitos, na detecção da bactéria nas sementes de soja.

O meio de cultura semi-seletivo MXG com e sem antibiótico não inibiu o crescimento de Xanthomonas axonopodis pv. glycines e o meio MXG com antibióticos foi eficiente para detecção da bactéria em sementes de soja, podendo ser usado em análises de rotina.

\section{REFERÊNCIAS}

1. Almeida, A.M.R.; ferreira, L.P.; Yorinori, J.T.; Silva, J.F.V.; Henning, A.A.; Godoy, C.V.; Costamilan L.M.; Meyer, M.C.; Doenças da soja. In: Kimati, H.; Amorin, L.; Rezende, J.A.M; Bergamin Filho, A.; Camargo, L.E.A. (Eds.) Manual de fitopatologia: doenças das plantas cultivadas. 4 ed. São Paulo: Agronômica Ceres Ltda, 2005, v.2, p.569-588.

2. Ferreira, D.F. Sisvar: a computer statistical analysis system. Ciência e Agrotecnologia, Lavras, v.35, n.6, p. 1039-1042, 2011.

3. Lopes, L.P.; Alves, P.F.R.; Zandoná, C.; Nunes, M.P. Meht, Y.R. Meio semi-seletivo para detectar Xanthomonas axonopodis pv. phaseoli em sementes de feijoeiro e sua erradicação através do tratamento de sementes com o fungicida tolylfluanid. Summa Phytopathologica, Botucatu, v. 34, n. 3, p. 287-288, 2008

4. Mehta, Y.R.; Bomfeti, C.; Bolognini, V. A semi selective medium to detect the presence of Xanthomonas axonopodis pv. malvacearum in a naturally infected coton seed. Fitopatologia Brasileira, Brasília, v.30, n.5, p. 489496, 2005.

5. Peixoto, A.R.; Mariano, R.L.R.; Viana, I.O. Meio semi-seletivo para isoi lamento de Xanthomonas campestris pv. viticola. Ciência Rural, Santa Maria, v.36, n.4, p.1317-1320, 2006.

6. Peron, A.P.; Santos, J.F.; Mantovani, D. Vicentini, V.E.P. Utilização das isoflavonas presentes na soja (Glycine max (L) Merril) na prevenção e tratamento de doenças crônicas - uma breve revisão. Arquivos do Museu Dinâmico Interdisciplinar, Maringá, v.12, n.2/3, p.51-57, 2012.

7. Prathuangwong, S.; Khandej, K., \& Goto, M. Development of new methods for ecological study of soybean bacterial pustule: A semiselective medium for detecting Xanthomonas campestris pv. glycines in contaminated soybean seed Proceedings of World Soybean Research. Chiangma, 1994. p. 197202. Disponível em: http://www.seedhealth.org/files/page/files/FIELD\%20 CROPS\%20v0815.pdfIn. Acesso em: 29 ago. 2011.

8. Rabalho, A.A. Xanthomonas spp. causadoras da mancha bacteriana do tomateiro (Lycopersicum esculentum Mill.): deteç̧ão em sementes e diferenciação. 2007. 92 p. Tese (Doutorado em Microbiologia Agrícola). Escola Superior de Agricultura "Luiz de Queiroz", Universidade de São Paulo, 2007.

9. Tebaldi, N.D.; Peters, J.; Souza, R.M.; Chitarra, L.G.; Zouwen, P.; Bergervoet, J.; Wolf, J. Detection of Xanthomonas axonopodis pv. phaseoli in bean seeds by flow cytometry applying immunostaining and direct viable counting. Tropical Plant Pathology, Brasília, v.35, v.4, p.213-222, 2010.

10. Tebaldi, N.D.; Souza, R.M.; Machado, J.C. Detecção de Xanthomonas axonopodis pv. phaseoli em sementes de feijão em meio de cultura semi-seletivo. Fitopatologia Brasileira, Brasília, v.32, n.1, p.56-58, 2007. 